\title{
Hairy Cell Leukemia (Morphologic and Immunophenotypic Profile)
}

\author{
Anindita Novia Damayanti, Arifoel Hajat \\ Department of Clinical Pathology, Faculty of Medicine, Airlangga University/Dr. Soetomo Hospital, Surabaya, Indonesia. E-mail: \\ aninditanovia89@gmail.com
}

\begin{abstract}
Hairy Cell Leukemia $(\mathrm{HCL})$ is a lymphoproliferative B cell abnormality dominated by mature lymphocytes with cytoplasmic projections and often misunderstood as Chronic Lymphocytic Leukemia (CLL). Misdiagnosis can be caused by errors in the preparation of peripheral Blood Smear Evaluation (BSE). Immunophenotyping is an option to differentiate $\mathrm{HCL}$ from CLL. A 56-year-old female presented with complaints of weakness. Physical examination showed conjunctival anemia and hepatosplenomegaly. Hematological test results were as follows: $\mathrm{Hb} 7.4 \mathrm{~g} / \mathrm{dL} ; \mathrm{WBC} 131.24 \times 10^{3} / \mathrm{uL} ;$ and PIt $61 \times 10^{3} / \mathrm{uL}$. BSE And Bone Marrow Aspiration (BMA) showed predominantly mature lymphocytes with cytoplasmic projections and suspected CLL with $\mathrm{HCL}$ as the differential diagnosis. Immunophenotyping with peripheral blood samples showed CD19+, CD20+, CD79a+, HLA-DR+, CD5-, and CD7- suggesting an increasing mature lymphocytes population (74.16\%) that expressed B lymphoid lineage. White Precursor Cell (WPC) channel test showed an abnormal lymphocytes population. The differential diagnosis of patients with dominant mature lymphocytes BSE with cytoplasmic projections was CLL and HCL. Immunophenotyping of CLL showed positive results on B cell markers (CD19, CD20, CD79a, and HLA-DR) with aberrant CD5. However, in such an $\mathrm{HCL}$ case like this, there were strongly positive results on B cell markers but the absence of aberrant CD5. This study was supported by the presence of abnormal lymphocytes population in the WPC test. The diagnosis of HCL in this patient was based on interpretation of BSE and immunophenotyping, supported by the WPC test.
\end{abstract}

Keywords: Hairy cell leukemia, chronic lymphocytic leukemia, immunophenotyping

\section{INTRODUCTION}

Hairy Cell Leukemia $(\mathrm{HCL})$ is a rare lymphoproliferative B cell disorder and is usually found in middle age (around 55 years of age). ${ }^{1}$ This abnormality is predominantly found in male compared to female with a ratio of $4-5: 1 .{ }^{2,3}$ The exact cause remains unknown. Clinical symptoms usually emerged are splenomegaly and pancytopenia. However, leukocytosis can also occur in some cases. The cell morphology of this disorder is characterized by small mature B lymphocytes with abundant cytoplasm and edges that represent cytoplasmic projections. ${ }^{1}$ The presence of cytoplasmic projections in Blood Smear Evaluation (BSE) of patients with Chronic Lymphocytic Leukemia (CLL) causes HCL to be often mistaken for a CLL.

This type of leukemia cell infiltrates the bone marrow and spleen. However, bone marrow is often difficult to aspirate. Bone marrow biopsy usually shows infiltration of hairy cells and a mixture of small lymphocytes and mast cells. Immunophenotyping can be used as the confirmation test of diagnosis to identify monoclonal mature $B$ cells more than $5000 / \mu \mathrm{L}$ as the B cell markers with no CD5 aberration. The diagnosis of $\mathrm{HCL}$ in this case report patient was confirmed by morphological examination to immunophenotyping.

\section{CASE}

A female with the age of 56 years old with main complaint weakness. Anamnesis: The patient came to the Outpatient Clinic of Dr. Soetomo Hospital Surabaya with complaints of body weakness three days before entering the hospital. She had a Loss of appetite. The patient also complained of an enlarged abdomen without pain (Figure 1). There were no complaints of bleeding, nausea, and vomiting. Normal bowel movements and urination were reported. Past medical history: Denied.

History of Laboratory Test and Inpatient Care (Table 1):

- August $8^{\text {th }}, 2018$ : Complete blood count test showed decreased $\mathrm{Hb}$ level, platelet count, and increased leukocyte count. The patient was then hospitalized for a blood transfusion. Blood Smear Evaluation (BSE) showed a predominance (82\%) of mature lymphocytes (mostly with cytoplasmic projections), $2 \%$ of lymphoblasts, and thrombocytopenia. The patient was suspected of $\mathrm{CLL}$ with $\mathrm{HCL}$ as a differential diagnosis. 
Therefore, further test using immunophenotyping was advisable.

- September $26^{\text {th }}, 2018: \mathrm{HCL}$ diagnosis was confirmed by BMA test. Bone marrow aspiration test outside the Department of Clinical Pathology, Dr. Soetomo Hospital, showed CLL with a predominance of mature lymphocytes (77.1\%). At the same time, the results from the Department of Clinical Pathology Dr. Soetomo Hopsital indicated a likeliness of $\mathrm{HCL}$ due to the dominance of mature lymphocytes with cytoplasmic projections.

- December 10 $0^{\text {th }}, 2018$ : The second BSE test showed the same conclusion, suggesting an $\mathrm{HCL}$ condition.

- December $11^{\text {th }}, 2018$ : BSE and BMA results were confirmed by immunophenotyping. An increased population of mature lymphocytes (74.16\%) expressing the $B$ lymphoid lineage without CD5 aberrations was reported.

\section{Physical examination: \\ General \\ condition : Adequate, compos mentis (GCS 15) \\ Vital signs : BP 110/60 mmHg; HR 80x/minute; RR 20x/minute; $t 36.5^{\circ} \mathrm{C}$ \\ Head/neck : Anemic conjunctiva, jugular distension -/- \\ Thorax : Cast and pulmo within normal limits \\ Abdomen : Distension, bowel sounds (+) normal, the spleen was palpable $\mathrm{S} 8 \mathrm{H} 4$, the liver was palpable two fingers under arcus costae \\ Extremities : Warm, CRT < 2 seconds, edema -/-}
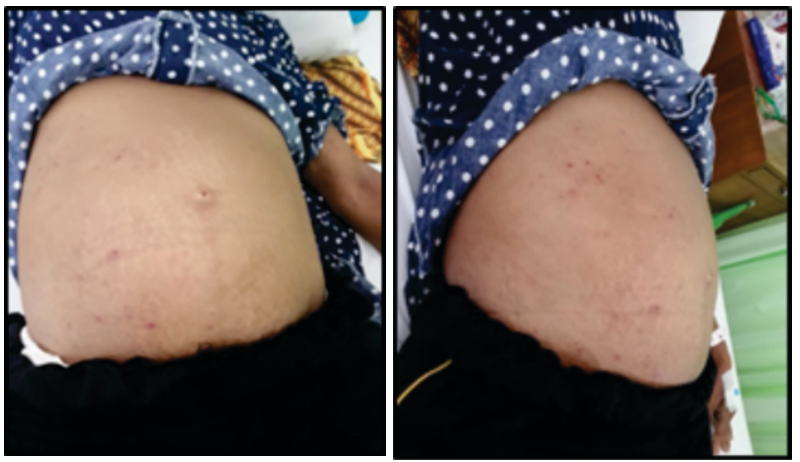

Figure 1. Abdominal distension with hepatosplenomegaly

\section{Additional Laboratory Tests:}

Table 2. BSE test on August $8^{\text {th }}, 2018$ (Dr. Soetomo Hospital)

\begin{tabular}{ll}
\hline Parameter & Results \\
\hline $\mathrm{Hb}$ & $7.3 \mathrm{~g} / \mathrm{dL}$ \\
WBC & $86.58 \times 10^{3} / \mathrm{uL}$ \\
Plt & $69 \times 10^{3} / \mathrm{uL}$ \\
\hline
\end{tabular}

RBC: Normochromic normocytic, anisopoikilocytosis (microcytes, ovalocytes, stomatocytes, fragmentocytes), polychromasia cells $(+)$, normoblasts $(+)$

WBC: Increased WBC count predominated with mature lymphocytes with the percentage of $82 \%$ (mostly with cytoplasmic projections) (Table 2, Fig 2). Two percent lymphoblasts, $12 \%$ prolymphocytes, $3 \%$ segmented neutrophils, $1 \%$ eosinophils were also found. PLT: Decreased PLT count. Giant platelet $(+)$. Interpretation: Anisopoikilocytosis normochromic normocytic anemia; Lymphocytosis with cytoplasmic projections; Thrombocytopenia. Conclusion: $\mathrm{CLL}$ dd/HCL was suspected. Suggestion: Immunophenotyping.

Table 1. Complete blood count test (Dr. Soetomo Hospital)

\begin{tabular}{lcccccl}
\hline Parameter & $\mathbf{8 / 8 / 1 8}$ & $\mathbf{1 8 / 9 / 1 8}$ & $\mathbf{1 0 / 1 2 / 1 8}$ & $\mathbf{2 1 / 0 1 / 1 9}$ & $\mathbf{2 9 / 0 1 / 1 9}$ & Reference Value \\
\hline $\mathrm{Hb}(\mathrm{g} / \mathrm{dL})$ & 7.3 & 9.2 & 7.4 & 7.7 & 10.3 & $\mathrm{~L} 13.3-16.6$ \\
& & & & & & $\mathrm{P} 11.0-14.7$ \\
$\mathrm{RBC}\left(10^{6} / \mathrm{uL}\right)$ & 2.71 & 3.38 & 2.62 & 2.58 & 3.65 & $3.69-5.46$ \\
$\mathrm{HCT}(\%)$ & 24.7 & 30.8 & 25.0 & 25.1 & 33.4 & $\mathrm{~L} 41.3-52.1$ \\
& & & & & & $\mathrm{P} 35.2-46.7$ \\
$\mathrm{MCV}(\mathrm{fL})$ & 91.1 & 91.1 & 95.4 & 97.3 & 91.5 & $86.7-102.3$ \\
$\mathrm{MCH}(\mathrm{pg})$ & 26.9 & 27.2 & 28.2 & 29.8 & 28.2 & $27.1-32.4$ \\
$\mathrm{MCHC}(\mathrm{g} / \mathrm{dL})$ & 29.6 & 29.9 & 29.6 & 30.7 & 30.8 & $29.7-33.1$ \\
$\mathrm{RDW}(\%)$ & 19.0 & 18.7 & 17.6 & 19.0 & 18.5 & $12.2-14.8$ \\
$\mathrm{Plt}\left(10^{3} / \mathrm{uL}\right)$ & 69 & 65 & 61 & 68 & 72 & $150-450$ \\
$\mathrm{WBC}\left(10^{3} / \mathrm{uL}\right)$ & 86.58 & 72.73 & 131.24 & 134.71 & 67.1 & $3.37-10$ \\
WBC diff count $(\%)$ & & & & & & \\
Eo/Baso/Neut/ & $1.8 / 0.1 /$ & $2.4 / 0.4 /$ & $1.2 / 0.3 /$ & $2.2 / 0.3 /$ & $2.0 / 0.1 /$ & Eo 0.6-5.4 \\
Lymph/Mono & $3.0 / 79.9 /$ & $2.9 / 80.7 /$ & $1.9 / 75.5 /$ & $1.7 / 55.5 /$ & $3.1 / 83.5 /$ & Baso 0.3-1.4 \\
& 15.2 & 13.6 & 21.1 & 40.3 & 11.3 & Neut 39.8-70.5 \\
& & & & & & Lymph 23.1-49.9 \\
& & & & & & Mono 4.3-10.0 \\
\hline
\end{tabular}




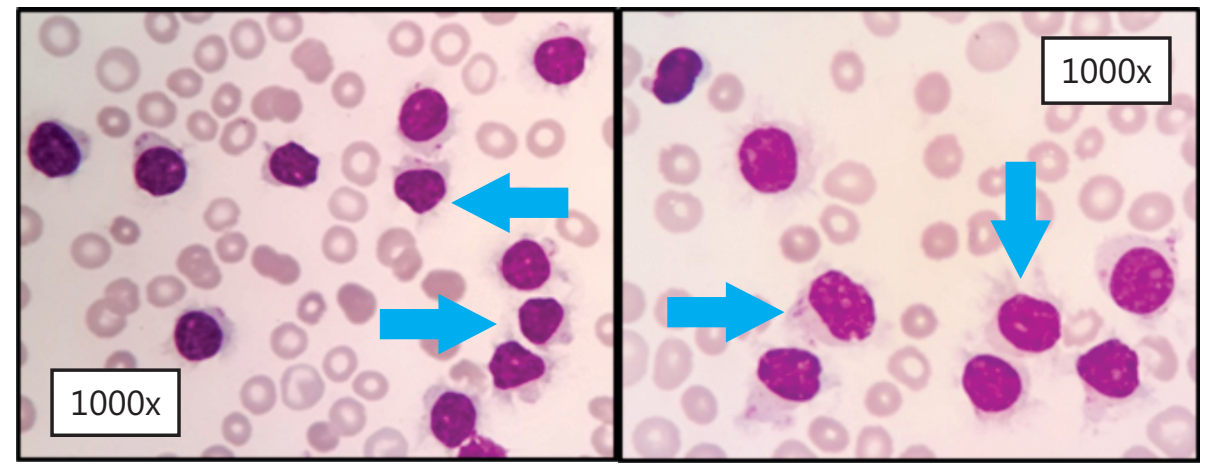

Figure 2. BSE predominated with mature lymphocytes with cytoplasmic projections in accordance with the characteristics of hairy cells (blue arrow)

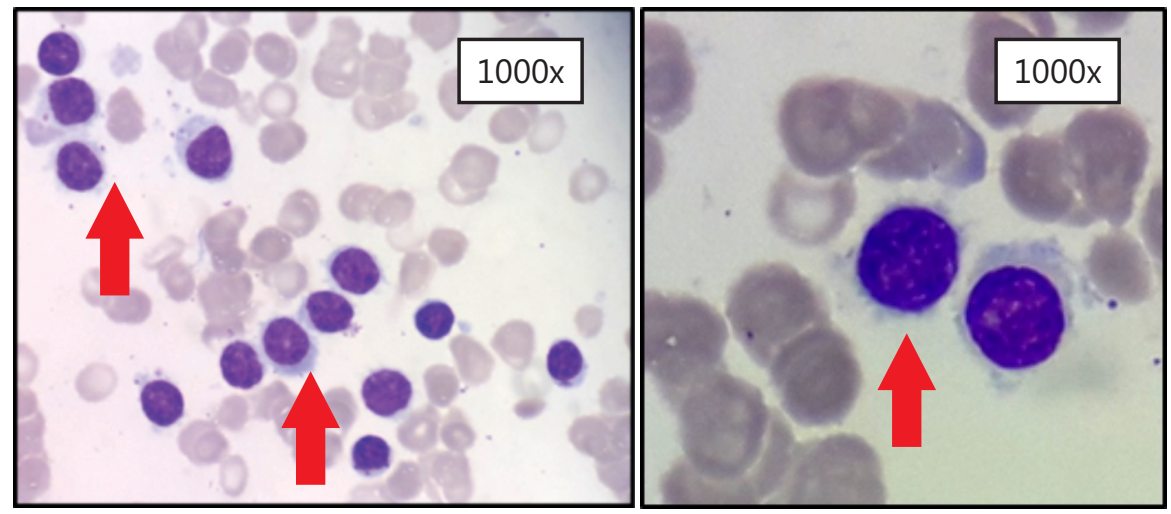

Figure 3. BMA predominated with hairy cells (red arrow). Non-hematopoietic cells were not found

BMA on September 26 ${ }^{\text {th }}, 2018$ (Dr. Soetomo Hospital) (Figure 3)

Cellularity

M:E ratio

: Hipocellular

$: 1: 1$

Erythropoiesis system : Decreased

Granulopoiesis system : Decreased

Megakaryopoiesis

: Decreased, megakaryocytes were hard to find

Other cells

Conclusions

: Non-hematopoietic cells were not found

: $\mathrm{HCL}$ with a predominance of mature lymphocytes with cytoplasmic projections.

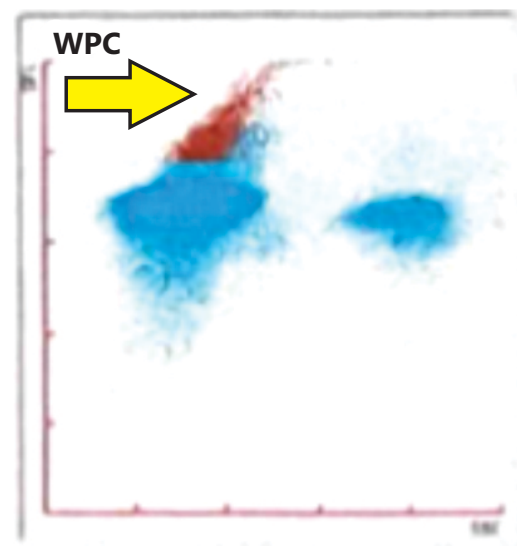

Table 3. BSE on December $10^{\text {th }}, 2018$ (Dr. Soetomo Hospital)

\begin{tabular}{ll}
\hline Parameter & Results \\
\hline $\mathrm{Hb}$ & $7.4 \mathrm{~g} / \mathrm{dL}$ \\
WBC & $131.24 \times 10^{3} / \mathrm{uL}$ \\
Plt & $61 \times 10^{3} / \mathrm{uL}$ \\
\hline
\end{tabular}

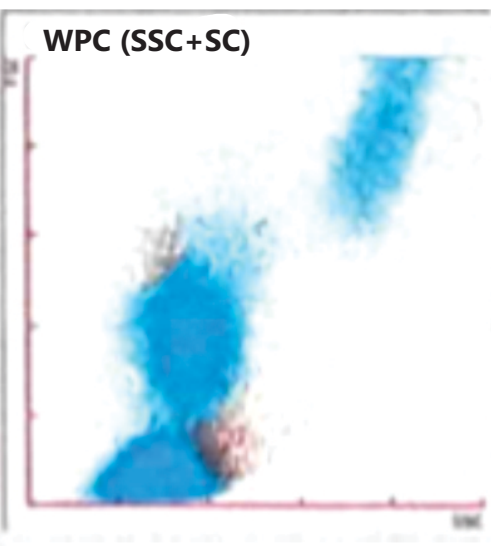

Figure 4. The red area on white precursor cell or WPC (yellow arrow) indicates an abnormal population of lymphocytes 

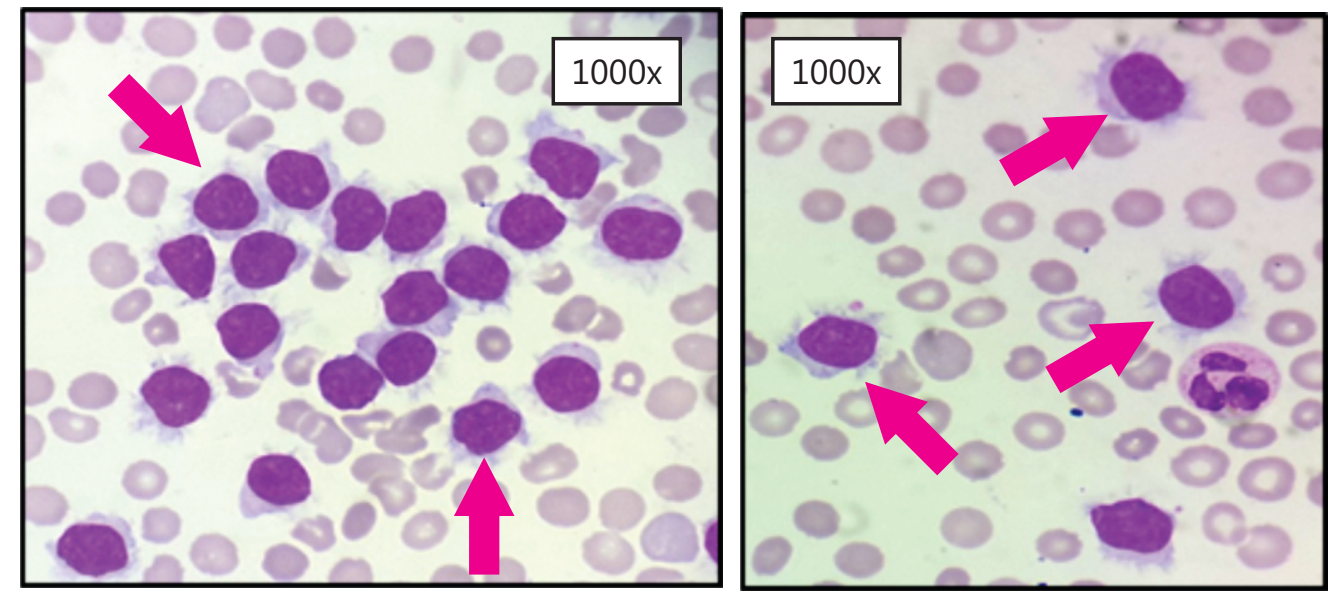

Figure 5. Further BSE results showing predominant hairy cells

Immunophenotyping on December $11^{\text {th }}, 2018$ (Dr. Soetomo Hospital)
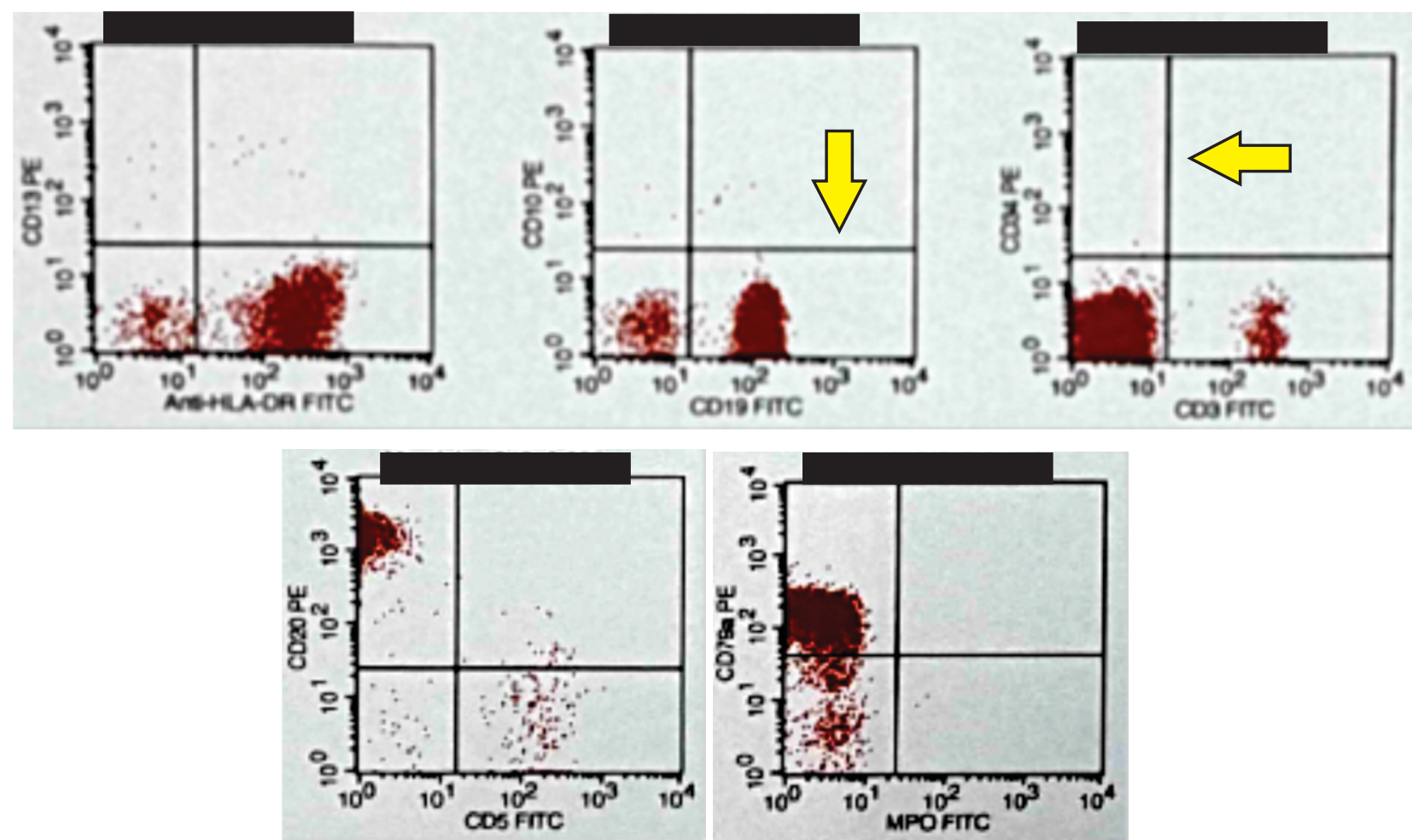

Figure 6. Positive immunophenotyping results are shown by the red population beyond the cut-off line (yellow arrow) of each parameter of each quadrant. Contrastingly, negative results are shown by the population within the cut-off line

RBC: Normochromic normocytic, anisopoikilocytosis (microcytic, ovalocyte, cigar cell), polychromasia cell $(+)$, normoblast $(+)$. WBC: Increased $\mathrm{WBC}$ count predominated with mature lymphocytes (as seen in WPC examination, Figure 4) with the percentage of $85 \%$ (mostly with cytoplasmic projections) (Table 3, Figure 5). Three percent prolymphocytes, $5 \%$ segmented neutrophils, 3\% eosinophils, and $4 \%$ monocytes were also found. PLT: Decreased PLT count. Giant platelet (-). Interpretation: Anisopoikilocytosis normochromic normocytic anemia; Lymphocytosis with cytoplasmic projections; Thrombocytopenia. Conclusion: $\mathrm{HCL}$ was suspected. Suggestion: Immunophenotyping (Table 4, Figure 5).

Table 4. The results of immunophenotyping

\begin{tabular}{llll}
\hline CD19 & + & CD5 & - \\
CD20 & + & CD7 & - \\
CD79a & + & HLA-DR & + \\
\hline
\end{tabular}

Note: There was an increased mature lymphocyte population (74.16\%) expressing B lymphoid lineage 
Management of the patient was given a PRC transfusion of 2 bags of blood within 24 hours until the $\mathrm{Hb}$ level reached $10 \mathrm{mg} / \mathrm{dL}$. The patient was also treated with an oral chemotherapy regimen, such as Fludarabine tablet ( $30 \mathrm{mg}$ ), once daily for five days.

\section{DISCUSSION}

Hairy cell leukemia is a chronic lymphoproliferative disorder that resembles and sometimes co-occurs with other hematological disorders. The diagnosis of $\mathrm{HCL}$ can be used as a differential diagnosis if there is a suspicion of other disorders such as aplastic anemia, hypoplastic myelodysplastic syndrome, atypical CLL, B-prolymphocytic leukemia, and idiopathic myelofibrosis. ${ }^{4}$ Hairy cell leukemia patients have varying clinical manifestations, commonly pancytopenia (with monocytopenia as a specific manifestation for $\mathrm{HCL}$ ) and splenomegaly, or without hepatomegaly and lymphadenopathy. Leukocytosis in this patient is a rare case and usually belongs to the less common $\mathrm{HCL}$ class, namely the $\mathrm{HCL}$ variant. ${ }^{5}$

The HCL neoplastic cells are medium-sized (slightly larger than small lymphocytes) with pale cytoplasm and characteristic cytoplasmic projections. The morphological features of hairy cells from several sources were similar to the BSE of the patient in this case (Figure 7). The nucleus is oval but is often kidney-shaped (reniform) or pea-like and clumped (granular), the chromatin is evenly dispersed, the nucleus is not conspicuous, and the nuclear membrane is smooth. ${ }^{3}$ Such morphologic findings of $\mathrm{HCL}$ are sometimes misdiagnosed as CLL due to an error in the process of making BSE and BMA preparations (Figure 8).

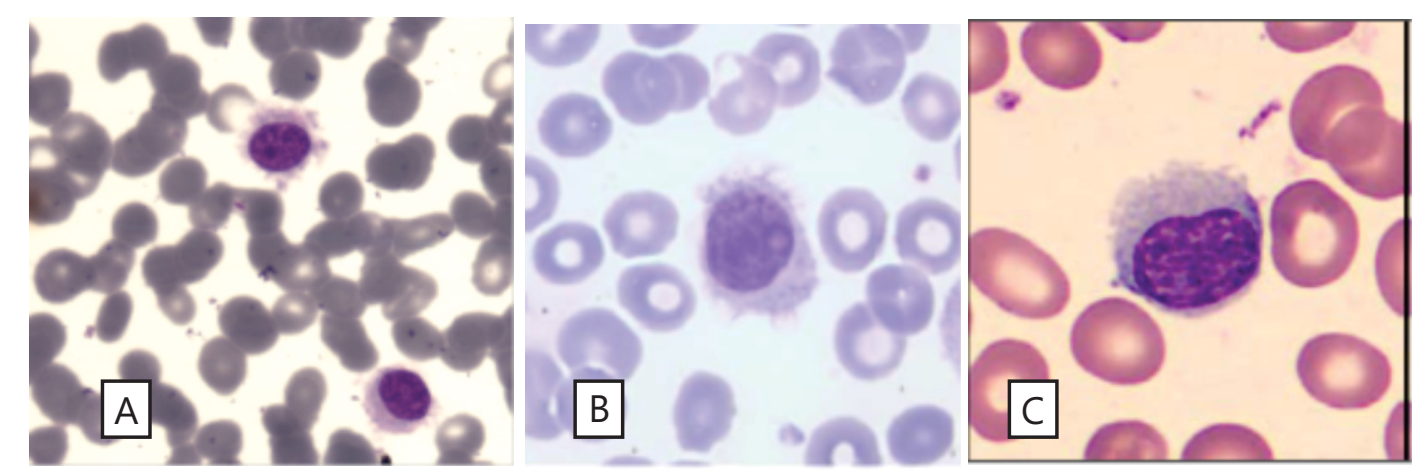

Figure 7. $(A),(B)$, and $(C)$ hairy cells from different references ${ }^{4-6}$

The morphological test results, in this case, were also supported by the results of the WPC channel on the Sysmex XN 1000 automated hematology analyzer. The white Precursor Cell channel can detect and differentiate blast cells and abnormal lymphocytes but cannot differentiate abnormal lymphocytes from cells due to chronic disorders. ${ }^{7-9}$

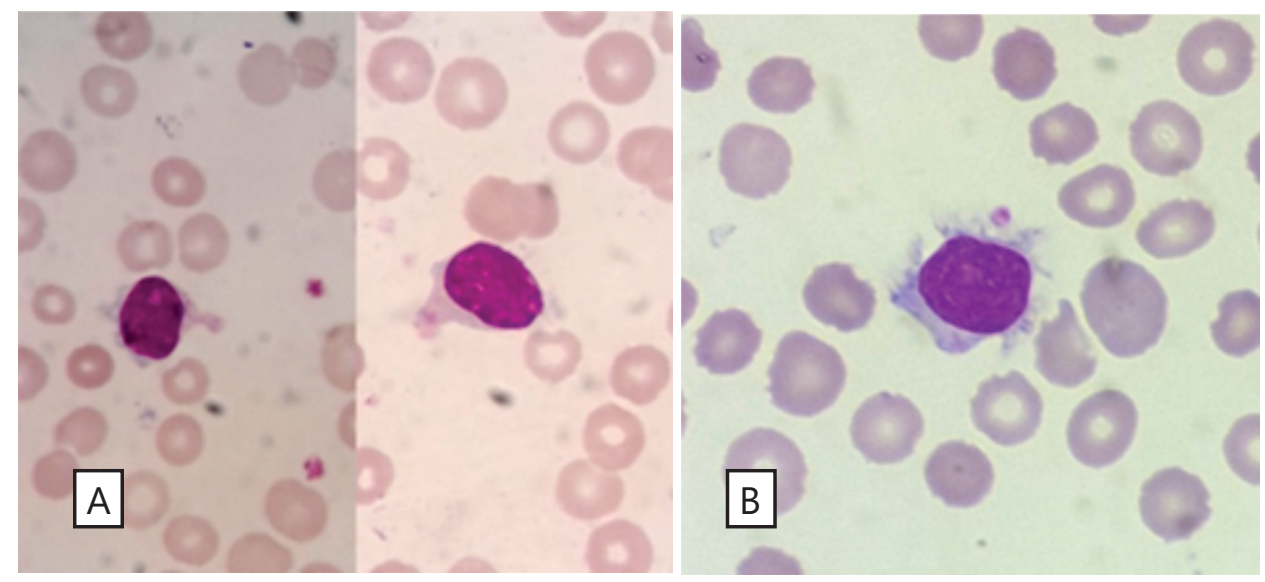

Figure 8. (A) Mature lymphocytes from BSE of CLL patients at Dr. Soetomo Hospital, which resembles hairy cells due to an error during the preparation of sample; (B) Hairy cells in this patient 
The patient, in this case, had an abnormal lymphocyte population, which was described as a red population over a blue population. This is because the abnormal lymphocyte cell membrane has a sufficient amount of phospholipid structure, making it easily penetrated by the Lysercell WPC reagent and can absorb a lot of dye from the Fluorocell WPC reagent, leading to a higher absorbance of fluorescence of abnormal lymphocyte cells compared to that of blast cells and other mature cells, which raises higher suspicion towards $\mathrm{HCL}^{7-9}$

Immunophenotyping was carried out as a further test to confirm the diagnosis of HCL. The immunophenotyping device used at the test only had several antigens, such as CD5, CD7, CD13, CD10, CD19, CD20, CD33, CD34, CD45, CD79a, MPO, and HLA-DR. The test results with this device showed that the patient, in this case, had CD19+, CD20+, CD79a+, and HLA-DR+, without expression of CD5 and CD7. Many kinds of literature state that $\mathrm{HCL}$ typically shows a strong positive expression of $B$ cell markers (CD19, CD20, CD22), coupled with strong expression of CD11c, CD25, CD103, tartrate-resistant acid phosphatase (TRAP, as indicated by immunohistochemical analysis or cytochemical staining), DBA-44, CD123, and annexin $\mathrm{A} 1 .^{1,3}$ These results were in line with a study by Mikler et al., which found that $\mathrm{HCL}$ patients showed expression of CD20+, CD79at, and CD5- by immunohistochemical staining, and the expression of CD19, CD20, CD22, CD25, FMD7, CD103, and lambda by flow cytometry. However, there was no expression of CD5, CD10, or kappa. ${ }^{6}$

It is important to note and remember that CD19, CD20, CD79, and HLA-DR are expressed by mature $B$ cells, whereas CD5 and CD10 are expressed by T3 cells. Therefore, $C D 5$ can be expressed in other B cell disorders such as CLL, but it is always negative in hairy cells. ${ }^{2}$ Such a result allowed the diagnosis of CLL in this patient to be ruled out because immunophenotyping revealed a robust positive $B$ cell marker but found no CD5 aberration.

\section{CONCLUSION}

The diagnosis of $\mathrm{HCL}$ in this patient was confirmed by morphological test (both BSE and BMA) with a predominance of mature B lymphocytes with cytoplasmic projections. In addition, WPC results supported the diagnosis, which showed a population of abnormal lymphocytes with high fluorescence. Immunophenotyping test showed positive results against mature $B$ cell markers in the absence of CD5 aberrations.

\section{REFERENCES}

1. Keohane EM, Smith LJ, Walenga JM. Rodak's hematology clinical principles and application. $5^{\text {th }} \mathrm{Ed}$., St. Louis, Elsevier, 2016; 628.

2. Jones G, Parry-Jones N, Wilkins B, Else M, Catovsky D. Revised guidelines for the diagnosis and management of hairy cell leukemia and hairy cell leukemia variant. British Journal of Haematology, 2012; 186-195.

3. Gorczyca W. Atlas of differential diagnosis in neoplastic hematopathology. $3^{\text {rd }}$ Ed., Boca Raton, CRC Press Taylor and Francis Group, 2014; 339-342.

4. Venkatesan S, Purohit A, Aggarwal M, Manivannan V, Tyagi $S$, et al. Unusual presentation of hairy cell leukemia: A case series of four clinically unsuspected cases. Indian J Hematol Blood Trans, 2014; 413-417.

5. Gaman AM, Dobrea CM, Gaman MA. A case report: A case of hairy cell leukemia variant. Rom J Morphol Embryol, 2015; 56(2): 553-556.

6. Broussard X, Cornet E. Hairy cell leukemia 2018: Update on diagnosis, risk-stratification, and treatment. Am J Hematol, 2017; 92: 1382-1390.

7. Matsushita H, Tanaka Y, Sakari K. Sysmex XN 1000 automated hematology analyzer: Clinical case report volume 1. Sysmex Asia Pacific, 2011; 4-70.

8. Noordegraaf $M$, Meijer $P$, Ruinemans-Koerts J. Diagnostic efficiency of the Sysmex XN WPC channel for the reduction of blood smears. Clin Biochem, 2016; 49(16-17): 1292-1294.

9. Provan D, Baglin T, Dokal I, de Vos J. Oxford handbook of clinical hematology. $4^{\text {th }}$ Ed., USA, Oxford University Press, 2015; 170-173. 